\title{
Impact of Occupation and Family Burden on Psychological Adjustment in Returning Migrants
}

\author{
Qiang Ren ${ }^{1}$, Tingting Wang², Jianfa Shen ${ }^{3}$, Wenfei Winnie Wang ${ }^{4}$, Yu \\ $\mathrm{Zhu}^{5,6}$
}

${ }^{1}$ Center for Social Research, Peking University, Beijing, China; 2Department of Sociology, Peking University, Beijing, China; 3 Department of Geography and Resource Management, the Chinese University of Hong Kong, Hong Kong SAR, China; 4 School of Geographic Science, University of Bristol, UK; ${ }^{5}$ School of Geography, Fujian Normal University, China; ${ }^{6}$ Asian Demographic Research Institute, Shanghai University, Shanghai, China.

Received 12/04/2019; Accepted 01/06/2020

\begin{abstract}
Background: Recently, increasing returning migrants in China accompany the massive rural-urban migration, but little information on mental health is available.

Methods: A cross-sectional survey was conducted in 2,100 households from seven provinces to examine the effect of return migration on mental health and its association with entrepreneurial experience, occupation, and family burden compared with local rural non-migrants. The 12-item General Health Questionnaire (GHQ-12) was used to measure mental health status, and factor scores were extracted through factor analysis to gauge three sub-domains of loss of confidence, social dysfunction, and anxiety. A general linear regression model was used to analyze the data for the association.
\end{abstract}

Results: Returning migrants were more likely to have elevated levels of anxiety compared with rural non-migrants when adjusting for social and demographic variables. Entrepreneurial experiences reduced loss of confidence and social dysfunction but increased anxiety; started but not currently running a business, and having older adults at home to care seemed growing concern in returning migrants but not in the rural non-migrants.

Conclusion: Our study supports the salmon bias effect, but that occupation, entrepreneurship, and family burden may have non-negligible impacts on the anxiety in returning migrants. The findings may have implications for promoting social integration for returning migrants.

\section{KEYWORDS}

Return migration; mental health; occupational health; family burden; general health questionare-12

\section{INTRODUCTION}

China has experienced a massive migration over the past decades. With the rapid urbanization and industrialization, a large number of residents have moved from rural to urban areas for employment or a better opportunity. This large-scale labor movement contributes to a significant portion of the rapid urbanization. According to the State Bur- eau of Statistics of China in 2016, the overall urbanization has reached $57.35 \%$ in China; the total number of migrant workers has reached at 282 million, of which 169 million work outside their hometown (e.g., county or district). However, the urbanization includes a dynamic cycle of "going into the city" and "returning to the home-town," and

${ }^{*}$ Correspondence to: Q Ren, Email: renqiang@pku.edu.cn 
return migration is an integral part of the massive ruralurban movement in China (1).

While return migration is a complex decision, the following reasons can explain the reasons for returning. First, Because of the existing urban-rural structure, hukou system, the segmentation of the urban labor market in China, migrants may have to experience various forms of social exclusion and social isolation, which makes it difficult for them to have a permanent living arrangement in the cities. Only a small number of migrants can eventually settle down in the city. As the migrants grow older, most of them have to return to the countryside $(2,3)$. Second, migration and returning are not only the result of decisions made by individuals to maximize personal income but also family decisions. Despite a recent trend that migrants tend to move with their family in China $(4,5)$, most of their children and parents have to remain at home in rural areas. Therefore, migrants may suffer from separation from their families. In addition, returning home is also a strategy to maximize family interests, including responding to care for older adults and children, family reunion, returning for marriage, or childbearing (6). Since the beginning of the rural-urban population movement in the $1980 \mathrm{~s}$, most of the migrants became old, the children left in the family have grown up, and their parents may need being taken care of. There will be an increasing number of returnees.

In addition, returning is an elastic strategy to deal with urban economic fluctuations. When the cities encounter a financial crisis or rise in unemployment, a large number of migrants had to temporarily or permanently return hometown. For example, previous studies in some provinces showed that due to the reform of state-owned enterprises in the 1990s, urban employment became difficult, and about one-third of the migrants had returned $(6,7)$. Further, affected by the 2008 financial crisis, a large number of manufacturers in the coastal cities were closed down, causing some migrants unemployed (8). Many migrants returned home as the state government provides policy support for entrepreneurship $(9,10)$. According to the Department of Floating Population Service Management of the former National Population and Family Planning Commission, as of December 20, 2008, the number of migrant workers returning home was 13.62 million, accounting for about $9 \%$ of the total rural migrant workers.

Previous studies have focused on migrants from rural to urban areas, but less attention has been paid to returning migrants. Even with a few studies of returning migrants, they have mainly focused on economic factors such as the reasons for returning $(2,3,11,12)$, and the occupational transition to examine if they are more inclined to be entrepreneurship, non-agricultural occupations as well as the impact on rural economic development $(3,13-15)$. How-

${ }^{1}$ Salmon is one type of fish that hatch in fresh water migrate to the ocean, then return to fresh water to reproduce. Scientists call healthy selective effect due to returning migrant as Salmon bias. ever, there are lacking research on the mental health and its associated factors in returning migrants

This study was to examine the effect of return migration, occupation, entrepreneurship, and family burden on mental health among returning migrants through a populationbased survey. The data was from a survey on 2,100 households randomly sampled from seven provinces of Guangdong, Hubei, Hunan, Henan, Sichuan, Anhui and Guizhou. The study would help local government to understand the health status of returning migrants and provide health services and eventually promote social integration.

\section{METHODS}

\section{Analytical framework}

Migration and mental health may have a complicated relationship in human populations. Previous studies have examined the mental health among staying migrants, mainly from two theoretical perspectives. The first one emphasizes the mediating role of relative deprivation, which affects the mental health of migrants. The relative deprivation is created by the change in social conditions in comparing with urban residents, which in turn affects mental health. Jin analyzed data from the 2012 China Labor-force Dynamics Survey (CLDS, $n=13,204$ ) and found that urban migrants tend to feel institutional isolation and social discrimination due to that they are inclined to compare with urban residents(16), thus, they suffer from relative deprivation and have lower happiness and poorer mental health (but no difference in social dysfunction) than urban residents, as well as rural non-migrants, do. Relative deprivation may induce migration, as a response to relative deprivation $(17,18)$. The second perspective emphasizes that migration is selective in health, i.e., the migration decision is closely associated with the health status of migrants, which is known as "healthy migrant" effect or that migrants have better health is due to "salmon bias" effect ${ }^{1}$

The "healthy migrant" effect ${ }^{2}$ was defined as "immigrants are in better health upon arrival in the destination than their local counterparts but that this health advantage erodes over time" (19). It implies that people with better health are more likely to migrate out of the rural areas to face the challenges moving into a new environment, which requires a better health condition to adapt (20). Meanwhile, doubt about the validity of the "healthy migrant" effect leads to the development of the "salmon bias" hypothesis (20), which proposes that those migrants with relatively poor health may choose to return, while those with better health are more likely to stay (21). As a result, compared with urban residents, migrants tend to have better physical and mental health conditions in spite of poor socioeconomic status.

\footnotetext{
2 It was originally defined for immigration, so we adopted it for
} domestic migration in this study. 
Qi et al. analyzed the data $(n=2,794)$ from China's Migration and Health Surveys (CMHS) in 2008 (22)and found that there are likely both "healthy migrant" effects and "salmon bias" effects in the migrants in China. Urban migrants generally have better self-reported health and lower risk of chronic diseases than those who have never migrated out of rural areas and urban residents, and they have a lower likelihood of suffering from chronic diseases and common physical ailments than those returning migrants do. However, there was no significant difference in mental health as measured by depressive symptoms among groups; a recent study of adult mortality risk (ages 30-90 years) between natives and internal migrants in the Netherland supports the "healthy migrant" effect but does not support the "salmon bias" hypothesis (20).

Studies have focused on the mental health of migrants and their association with migration. However, the migration process may have a continuous or cumulative impact on an individual's mental health, even when they return home. Therefore, the mental health of returning migrants is worthy of study. By directly comparing the mental health status between returning migrants and rural non-migrants, one can examine the subsequent impact of the migration on mental health among returning migrants.

According to the health selection hypothesis, the "salmon bias" effect is a negative selection process for returning migrants, while the "healthy migrant" effect is a positive selective process for migrants. The positive selection of "healthy migrant" occurred first before the "salmon bias" adverse selection, so the mental health status of returning migrants should be better than that of rural non-migrants. This presupposes that the mental health of migrants is a fixed personality trait, and will not undergo qualitative changes with the migration experience and duration of returning. This hypothesis may need a further empirical study to validate. On the other hand, according to the mediating theory of relative deprivation, the impact of the migration experience on the individual's mental health is continuous. Returning migrants may have adopted an urban frame of reference; after returning, they are still inclined to refer to the urban residents, resulting in a stronger sense of relative deprivation and poorer mental health. Jin found that the relative deprivation of returning migrants is stronger than that of rural non-migrants, and this may reduce the levels of happiness in returning migrants compared with urban residents and rural non-migrants (16). The relative deprivation has been proposed as the psychosocial pathway that links the migration and psychosocial wellbeing in the migrants and therefore affects the function of social roles.

Therefore, we propose, that the mental health status of returning migrants is worse than that in the rural nonmigrants is.

The view that the returning migrants tend to refer to the urban residents is worthy of further study. As time goes, the reference group of returning migrants is likely to change. They may choose non-migrants in their hometown as a reference group rather than urban residents. Thus, the returning migrants are more likely to compare with the surrounding non-migrants, and the mediating effect of relative deprivation is likely weakened or eventually diminished. In addition, when returning migrants use the rural non-migrants as a reference, the type of occupation and the family burden will be important factors. The difference in occupation and family burden between returnees and rural non-migrants may have more impact that is significant on mental health. As far as the occupation is concerned, non-agricultural workers or entrepreneur-ship may affect the mental health status.

However, previous studies of both entrepreneurial experiences and family burdens have shown positive and negative impacts on mental health. The negative impact is because that entrepreneur may face more risk, pressure, and role conflicts, consuming more emotional energy, so that they have more significant psychological stress and poorer mental health $(23,24)$. In addition, the elderly and children who need care will increase the family burden and the psychological pressure of family caregivers (usually the family labor) (25). In contrast, the positive impact assumes that entrepreneurs may have higher job satisfaction and selfefficacy. As a result, entrepreneurship has a positive effect on mental health such as lower levels of depression and more job satisfaction $(26,27)$. Moreover, the elderly and children at home can give family labor emotional support, which may improve the mental health of family caregivers (28).

Whether the entrepreneurship and family burdens play a positive or negative role in the mental health of returning migrants remains to be tested. We further propose that: 1 ) There are differences in the mental health of returning migrants by occupation; 2) Entrepreneurship negatively impact on the mental health of returning migrants; 3 ) The family burden negatively impact on the mental health of returning migrants overall.

\section{Study design and participants}

The data used for analysis were from the survey of the research project, Impact of Urban-Rural Return Migration on Rural Economic Development in China - With Implications for Vietnam, conducted by the Center for Social Research of Peking University between April and August 2015 in Guangdong, Hubei, Hunan, Henan, Sichuan, Anhui, and Guizhou Provinces of China. These provinces are the central regions that contributed to labor migrants, and returning migrants have become increasingly common in the past few years. Geographically they present a spatially broad coverage, with one from coastal, three from inland, and two from the western area of China. They also represent different levels of economic development, with Guangdong being one of the most developed provinces, Guizhou, one of the least developed areas in China.

This survey was designed using multi-stage stratified random sampling and randomly selected three counties from each province according to economic indicators. Each county randomly selected five villages according to the geographical location and the distance from the urban center, and then each drew 15 households with at least one retur- 
ning migrant for interview. Of 15 families within each village, five were selected as recommended by the village leader; the remaining ten households, in which five households without migrants, are randomly drawn according to a list of the roster provided by village or the snowball method (without the roster). Selected returning migrants to be interviewed must meet three criteria:1) be a local rural resident before migrating out; 2) have been lived in the village consecutively for more than one year after leaving the original place of residence; 3 ) have settled down continuously in the hometown (including county towns or townships) for more than one year after returning. In total, 2,216 persons among 105 villages in 21 counties were interviewed face to face for the survey. Research participants of this study are returning migrants and rural nonmigrants. We defined returning migrant as an individual who had migrated out to work for at least one year and have returned to hometowns (including county towns and townships) for at least one year. The non-migrants were defined as people who had worked in the local area for a long time, over 18 years old, and have no work experience out of the original residence.

\section{Outcomes and measurements}

\section{General mental health}

The psychosocial adjustment was measured by the general mental health of respondents in recent weeks using the 12item General Health Questionnaire (GHQ-12), which is one of the most popular and widely used screening instruments for recognition and measurement of mental health (29). It was originally developed by Goldberg to screen subjects for psychiatric illness for case identification $(30,31)$. GHQ12 has been validated in general population surveys of both younger and older Chinese populations $(32,33)$. The GHQ-12 consists of 12 items, including positive and negative elements, measuring the self-confidence, anxiety, and psychological aspects of daily social interactions (34). Each scale is based on a four-point Likert scale $(0,1,2,3)$; the total score ranges from 0 to 36 ; a higher score indicates a lower level of mental health $(34,35)$.

The overall GHQ-12 is developed as a one-dimensional measurement(36). However, follow-up studies have shown that three dimensions underlying GHQ-12: loss of selfconfidence, social dysfunction, and anxiety (37). Naturally treating GHQ-12 score as one-dimensional measure may hide the exact internal structure of general mental health. However, an empirical analysis of data from the 2008 wave of the Rural to Urban Migration in China (RUMiC) survey showed that GHQ-12 was a two dimension-coping/engagement and stress/depression model (38). Also Guan et al analyzed the large sample of 2009 RUMiC survey (n> 32,171 ) stratified by age, number of siblings and number of children and showed that 2-3 factor structure model have a good fit of GHQ-12 score, although the first factor explained much larger variation(39).

Factor analysis was performed to identify the internal structure of GHQ-12. Before factor analysis, KMO (Kaiser-Meyer-Olkin) and Bartley sphericity tests were performed to test for the reliability of items that also determine the suitability for factor analysis. KMO (Kaiser-Meyer-Olkin) was used to determine whether the data is suitable for factor analysis; a larger KMO value indicates more common factors among these variables, suggesting more ideal for factor analysis. We used Graetz's maximum likelihood estimation with the oblique rotation method (37) to extract interpretable dimensions that underlie the data structure with minimal loss of information.

\section{Explanatory variables}

Explanatory variables were selected to test for the hypothesis and consisted of three dimensions. Specifically, they included the migration status, occupation, occupational and entrepreneurial experiences. The migration status was coded as a binary variable. Occupation was classified as agricultural and non-permanent employment (e.g. agriculture, forestry, animal husbandry, fishery, water conserveancy production and non-permanent employees), hightech company professional (e.g. management, clerks, professional and technical personnel), low-tech (commercial service, manufacturing, construction workers, transport equipment operators), self-employed (self-employed households, urban street vendors), other non-classified workers. Entrepreneurial experience is divided into never started a business, started a business but not currently running a business, and have started and now running a business. The family burden included whether have an older adult (aged over 65 years) at home to be taken care of and whether have a child of age under 15 years old at home.

Some other variables were selected to control for potential confounding effects. These include gender, age, years of education, marital status, annual household income per capita, self-assessment of general health, self-assessed economic situation at family, and county level. Age was grouped into an ordinal or categorical variable, with age below 30 years old as a reference group, 30 to 44 years, and 45 years and above. Years of education was coded as a continuous variable, no school (0 years), primary school (6 years), and junior high school ( 9 years), high school /vocational school (12 years), college (15 years), undergraduate (16 years), postgraduate or above (19 years). Marital status was a binary variable coded as 0 if no marriage (including un-married, divorced, and widowed) and 1 if currently married (including married and remarried). Household income per capita last year was coded as an interval variable. The region is a dummy variable by 21 counties. Other control variables included gender (male=1), self-reported health status (coded as very poor or bad $=1 ; 0$ otherwise), self-reported household economic status (coded as 1 if below the median; 0 otherwise).

\section{Statistical analysis}

The analysis strategy was divided into three steps. With rural non-migrants as a reference group, we first compared returning migrants with the reference to examine if there were any significant difference in the key demographic and socioeconomic variables, including individual characteristics, gender, age, education, marital status, self- 
reported general health, household income per capita last year, self-reported family economic status, type of occupation, family burden such as having old adults or child to care at home, and entrepreneurial experience. Then, using the variance of analysis and regression analysis, we compared the differences in general mental health to assess the psychological adjustment in the returning migrants.

The modeling was divided into three steps. The Model 1 was an initial model with only returning migration as a binary variable, equivalent to a variance of analysis ( 1 if returning migrant; 0 otherwise); Model 2 is a regression model controlling for demographic and socioeconomic variables; Model 3 simultaneously controlled for demographic and socioeconomic variables, occupation, and family burden variables. Finally, we examined the determinants of the general mental health in returning migrants and rural nonmigrants, separately.

\section{RESULTS}

\section{Descriptive statistics}

Due to missing values in some variables, the valid sample size was 2,183 , including 1,615 households with at least one returning migrant and 568 families without migrants (Table 1). Generally, the proportion of men is higher for both returning migrants and non-migrants than that of women in six provinces, excluding returning migrants in Hubei.

Table 1. Sample distribution by sex and region

\begin{tabular}{|c|c|c|c|c|c|c|}
\hline & \multicolumn{2}{|c|}{ Combined } & \multicolumn{2}{|c|}{ Returning migrants } & \multicolumn{2}{|c|}{ Non-migrants } \\
\hline & $\mathrm{N}$ & $\%$ of male & $\mathrm{N}$ & $\%$ of male & $\mathrm{N}$ & $\%$ of male \\
\hline Anhui & 340 & 57.4 & 248 & 60.1 & 92 & 50.0 \\
\hline Guangdong & 286 & 68.9 & 212 & 65.1 & 74 & 79.7 \\
\hline Guizhou & 303 & 79.5 & 226 & 81.9 & 77 & 72.7 \\
\hline Henan & 303 & 68.3 & 225 & 69.3 & 78 & 65.4 \\
\hline Hubei & 318 & 49.7 & 239 & 47.3 & 79 & 57.0 \\
\hline Hunan & 327 & 60.9 & 240 & 58.3 & 87 & 67.8 \\
\hline Sichuan & 306 & 59.5 & 225 & 62.7 & 81 & 50.6 \\
\hline Total & 2,183 & 63.2 & 1,615 & 63.3 & 568 & 62.9 \\
\hline
\end{tabular}

Table 2 presents the coding and descriptive statistics of individual independent variables and covariates of the survey participants. The mean age of returning migrants was 40 years old, which was younger than that in rural non-migrants (46 years). A slightly higher proportion ( $8.4 \%$ ) of non-married individuals in the returning group compared with the rural nonmigrant group (3.4\%). Returning migrants reported a higher level of good health $(90.7 \%)$ than rural non-migrants did $(81.9 \%) ; 61 \%$ of returning migrants had a child to care at home, higher than those rural non-migrants did $(44.7 \%)$. These all were likely due to younger age in the returning migrants.

We did not found any marked difference between returning migrants and rural non-migrants in other variables such as years of education (8.5 vs. 8.9 years), annual household income per capita (mean, 12,000 to 13,000 RMB), gender distribution, the self-assessed family economic status, type of occupation and entrepreneurial experience, and whether have an elderly at home to care.

\section{GHQ-12 and factor analysis}

We examined individual GHQ-12 item by returning status, province and proportion of individuals who reached at a cutoff ( $>=14$ ) (Table S1, Table S2). The general GHQ-12 score is round 8.8; there is 9.8 percent of people with GHQ12 score at 14 or more. The proportions of those with higher GHQ-12 score in Anhui, Hubei, Sichuan, and Guizhou are higher than average level. For returning migrants, the proportions over average occur in Hubei, Sichuan and Guizhou. For non-migrants, the proportions over average are Anhui, Hubei and Sichuan.

Analysis of the GHQ-12 score indicated that KMO was 0.84 and Bartlett's sphericity test was significant (Chi-square =
7244.42 , degrees of freedom $=66, p<0.0001$ ), indicating that our GHQ-12 data were suitable for performing factor analysis.

Table 3 shows the factor analysis of GHQ-12. Three factors with eigenvalue greater than 1 explained $66.03 \%$ of the total variance in GHQ-12 items. According to the factorloading matrix and the loading values of each item on individual factors, we defined the first factor as loss of confidence, the second factor as social dysfunction, and the third one as anxiety or depression. The factor score ranged from 0 to 1 .

\section{Differences in psychological adjustment by the status of returning migration}

Table 4 shows the differences in the overall GHQ-12 score between returning migrants and rural non-migrants and by other covariates. It was shown that there were no significant differences in the GHQ-12 between groups by age, sex, marital status, self-assessed household economic status, and self-reported health, type of occupation, entrepreneurial experience, older adults, or child at home to care. These were mostly consistent with that in Table 2.

However, we did observe female returning migrants (Mean=9.82; $S D=4.6$ ) had a better general mental health than female rural non-migrants did $(\mathrm{p}<0.05)$. Female returning migrants also tended to have a better health status if they were engaged in the agricultural sector, high-tech company professionals, or had elderly care at a nominal level of significance $(\mathrm{p}<0.1)$. 
Table 2. Descriptive statistics of independent variables

\begin{tabular}{|c|c|c|c|c|c|c|}
\hline \multirow[b]{2}{*}{ Coding } & \multicolumn{3}{|c|}{ Returning migrant } & \multicolumn{3}{|c|}{ Rural non-migrant } \\
\hline & $\mathrm{N}$ & $\% /$ Mean & SD & $\mathrm{N}$ & $\%$ & SD \\
\hline Age & 1615 & 39.6 & 10 & 568 & 46 & 9.6 \\
\hline $1=$ Less than 30 years & 305 & 18.9 & & 38 & 6.7 & \\
\hline $2=30-44$ years & 770 & 47.7 & & 184 & 32.4 & \\
\hline $3=$ Above 44 years & 540 & 33.4 & & 346 & 60.9 & \\
\hline Education (years) & 1615 & 8.9 & 3 & 568 & 8.5 & 3.4 \\
\hline Annual household income per capita (RMB) & 1615 & 12,610 & 27,710 & 568 & 12,970 & 44,640 \\
\hline \multicolumn{7}{|l|}{ Gender } \\
\hline $0=$ Female & 593 & 36.7 & & 211 & 37.2 & \\
\hline $1=$ Male & 1022 & 63.3 & & 357 & 62.8 & \\
\hline \multicolumn{7}{|l|}{ Marital status } \\
\hline $0=$ Unmarried, divorced/widowed & 135 & 8.4 & & 21 & 3.7 & \\
\hline $1=$ Married or remarried & 1480 & 91.6 & & 547 & 96.3 & \\
\hline \multicolumn{7}{|l|}{ Self-assessed family economic status } \\
\hline $0=$ Median and above the median & 1281 & 79.3 & & 417 & 73.4 & \\
\hline $1=$ Below the median & 334 & 20.7 & & 151 & 26.6 & \\
\hline \multicolumn{7}{|l|}{ Self-reported health } \\
\hline $0=$ Very good/good/median & 1465 & 90.7 & & 465 & 81.9 & \\
\hline $1=$ Very poor/bad & 150 & 9.3 & & 103 & 18.1 & \\
\hline \multicolumn{7}{|l|}{ Occupation } \\
\hline 1=Agricultural/non-permanent employment & 895 & 55.4 & & 325 & 57.2 & \\
\hline 2=High-tech company professional & 143 & 8.9 & & 38 & 6.7 & \\
\hline 3=Low-tech company professional & 220 & 13.6 & & 60 & 10.6 & \\
\hline $4=$ Self-employed & 310 & 19.2 & & 102 & 18 & \\
\hline $5=$ Others & 47 & 2.9 & & 43 & 7.6 & \\
\hline \multicolumn{7}{|l|}{ Entrepreneurial experiences } \\
\hline $1=$ Never started a business & 831 & 51.5 & & 323 & 56.9 & \\
\hline $2=$ Started but not currently running a business & 719 & 44.5 & & 202 & 35.6 & \\
\hline $3=$ Started and currently running a business & 65 & 4 & & 43 & 7.6 & \\
\hline \multicolumn{7}{|l|}{ Having an elderly at home (aged 65 years or older) } \\
\hline $0=$ No & 1237 & 76.6 & & 444 & 78.2 & \\
\hline $1=$ Yes & 378 & 23.4 & & 124 & 21.8 & \\
\hline \multicolumn{7}{|l|}{ Having a child at home (aged 15 years or under) } \\
\hline $0=\mathrm{No}$ & 629 & 39 & & 314 & 55.3 & \\
\hline $1=$ Yes & 986 & 61 & & 254 & 44.7 & \\
\hline
\end{tabular}

Table 3. Description and summary statistics of three factor and GHQ-12 score

\begin{tabular}{|c|c|c|c|c|c|}
\hline Factor & Factor meaning & Items & $\%$ & Mean & SD \\
\hline Overall & & Item 1-12 & & 8.78 & 4.47 \\
\hline $\begin{array}{l}\text { Loss of } \\
\text { confidence }\end{array}$ & $\begin{array}{l}\text { Loss of confidence, } \\
\text { low self-esteem }\end{array}$ & $\begin{array}{l}\text { Item } 11.12 \text {. } \\
\text { (Been losing confidence in yourself. Been thinking of } \\
\text { yourself as a worthless person) }\end{array}$ & 25.91 & 0.41 & 0.58 \\
\hline $\begin{array}{l}\text { Social } \\
\text { dysfunction }\end{array}$ & $\begin{array}{l}\text { Social dysfunction, } \\
\text { loss of pleasant }\end{array}$ & $\begin{array}{l}\text { Item 3.4.5.6. } \\
\text { (Been able to concentrate on whatever you are doing. } \\
\text { Felt that you are playing a useful part in things. Be } \\
\text { able to face up to your problems. Felt capable of } \\
\text { making decisions about things.) }\end{array}$ & 20.77 & 0.89 & 0.42 \\
\hline Anxiety & Anxiety, depression, & $\begin{array}{l}\text { Item } 1.2 \text {. } \\
\text { (Lost much sleep over worry. Felt constantly under } \\
\text { strain.) }\end{array}$ & 19.35 & 0.96 & 0.77 \\
\hline
\end{tabular}

$\%$, the proportion of variation explained by the individual factor 
Table 4. Descriptive statistics of total GHQ-12 score by migration, demographics and covariates

\begin{tabular}{|c|c|c|c|c|c|}
\hline & Returnin & & Rural non & & \\
\hline Coding & Mean & SD & Mean & SD & Sig. \\
\hline Age & & & & & \\
\hline $1=$ Less than 30 years & 9.42 & 4.21 & 9.18 & 4.11 & \\
\hline $2=30-44$ years & 9.53 & 4.32 & 9.51 & 4.55 & \\
\hline $3=$ Above 44 years & 9.79 & 5.10 & 10.14 & 5.52 & \\
\hline Gender & & & & & \\
\hline $0=$ Female & 9.82 & 4.60 & 10.61 & 5.41 & ** \\
\hline 1=Male & 9.47 & 4.56 & 9.44 & 4.93 & \\
\hline Marital Status & & & & & \\
\hline $0=$ Unmarried, divorced or widowed & 10.13 & 4.63 & 11.48 & 5.27 & \\
\hline $1=$ Married or remarried & 9.55 & 4.57 & 9.87 & 5.13 & \\
\hline Self-assessed family household status & & & & & \\
\hline $0=$ Median and above the median & 9.12 & 4.18 & 9.17 & 4.71 & \\
\hline $1=$ Below the median & 11.45 & 5.48 & 11.82 & 5.77 & \\
\hline Self-assessed health & & & & & \\
\hline $0=$ Very good/good/median & 9.19 & 4.22 & 9.05 & 4.60 & \\
\hline $1=$ Very poor $/$ bad & 13.61 & 5.84 & 13.61 & 5.77 & \\
\hline Occupation & & & & & \\
\hline 1=Agricultural/non-permanent employment & 9.97 & 4.95 & 10.57 & 5.56 & $*$ \\
\hline 2=High-tech company professional & 9.79 & 3.99 & 8.42 & 3.87 & * \\
\hline 3=Low-tech company professional & 8.98 & 3.80 & 9.68 & 4.14 & \\
\hline $4=$ Self-employed & 8.84 & 4.13 & 8.47 & 5.59 & \\
\hline $5=0$ thers & 9.74 & 4.23 & 8.47 & 5.59 & \\
\hline Entrepreneurial experiences & & & & & \\
\hline $1=$ Never started a business & 10.03 & 4.77 & 10.25 & 5.43 & \\
\hline $2=$ Started but not currently running a business & 9.20 & 4.22 & 9.28 & 4.42 & \\
\hline $3=$ Started and currently running a business & 8.57 & 5.25 & 9.84 & 5.88 & \\
\hline Having an elderly at home (aged 65 years or older) & & & & & \\
\hline $0=\mathrm{No}$ & 9.42 & 4.45 & 9.88 & 5.15 & * \\
\hline $1=$ Yes & 10.18 & 4.95 & 9.85 & 5.13 & \\
\hline Having a child at home(aged 15 years or under) & & & & & \\
\hline $0=\mathrm{No}$ & 9.72 & 4.75 & 9.91 & 5.24 & \\
\hline $1=$ Yes & 9.52 & 4.46 & 9.82 & 5.03 & \\
\hline
\end{tabular}

*** $\mathrm{P}<0.01,{ }^{* *} \mathrm{P}<0.05,{ }^{*} \mathrm{P}<0.1$

We performed a regression analysis to examine the association of returning migrant status with the overall GHQ-12 score and three sub-domain scores: loss of confidence, social dysfunction, and anxiety (Table 5). It is interesting to note in Model 1, even when returning migrant status was not significantly associated with the overall GHQ-12 score, we found that returning migrants were less likely with loss of confidence $(p<0.05)$ and social dysfunction $(p<0.05)$, which might imply that returning migrants had more confidence and performed better in social function.

Controlling for general demographic and socioeconomic variables (Model 2), we found that returning migrants tend to show elevated levels of anxiety or depression (Coef. = $0.026 ; p<0.05)$. Unfortunately, returning status was no longer associated with the loss of confidence $(p<0.392)$ and social dysfunction $(\mathrm{p}=0.881)$. However, further when occupation, entrepreneurial experience, and family burden were controlled (Model 3), the effect of returning status on the levels of anxiety was reduced but still at a level close to significance (Coef. $=0.023 ; p=0.066$ ). This might imply that the association of returning status with anxiety was parti- ally due to occupation, entrepreneurial experience, and family burden.

\section{Determinants of psychological adjustment by returning status}

We examined the determinants of the general mental health in returning migrants and found that returning migrants with poor self-assessed health and lower self-assessed family socioeconomic status were significantly associated with all three sub-domains of loss of confidence, social dysfunction and anxiety (Table 6a).

Occupation had no effect on the loss of confidence and social dysfunction but significantly affected the level of anxiety in returning migrants. Compared with the returning migrants who were engaged in the agricultural/non-permanent employment, those who were high-tech company professionals were more likely associated with anxiety (Coef. $=0.07 ; p<0.01$ ) but low-tech company professional was less likely associated with anxiety (Coef.=-0.049; $\mathrm{p}<0.01$ ). 
Table 5. Regression analysis of GHQ-12 score by migration

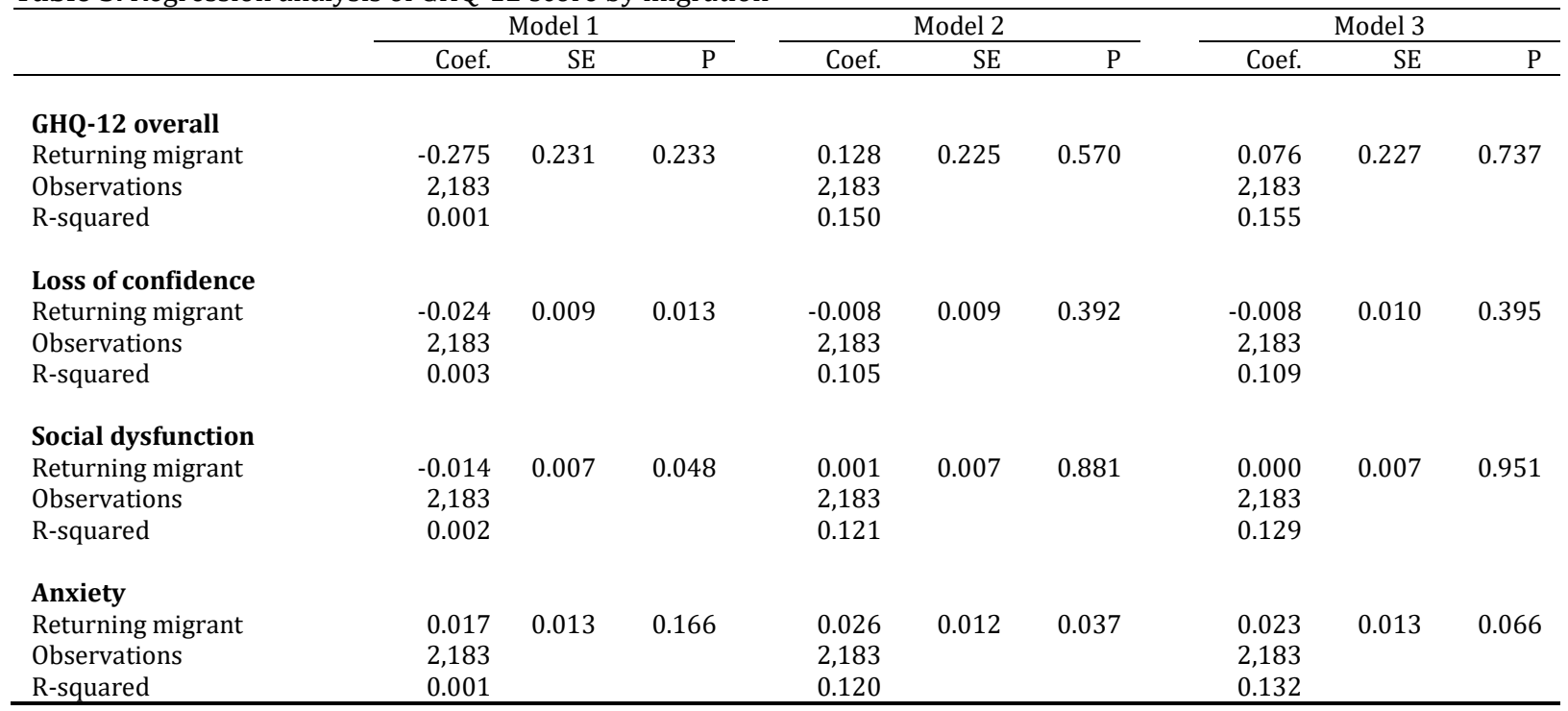

a. Model 1 includes only migration status;

b. Model 2 is a model that controlled for general demographic and socioeconomic variables, including gender, age, years of schooling, marital status, per capita yearly household income, self-assessment of general health status, self-assessment of family economic status, and regional social variables of the population;

c. Model 3 is a model that further controlled for type of occupation, entrepreneurial experiences, and whether there are elderly and children at home based on Model 2.

Entrepreneurial experience affected mental health differently in sub-domains. Compared with those never started a business, returning migrants who had started but not currently running a business (Coef. $=-0.025 ; p<0.01$ ) and started but presently running a business (Coef. $=-0.070$; $p<0.01$ ) tend to have reduced likelihood of losing confidence. Similarly, returning migrants who had started but not currently running a business (Coef. $=-0.023$; $p<0.01$ ) and started but presently running a business (Coef.=-0.070; $p<0.01$ ) also tend to have reduced likelihood of social dysfunction. In contrast, returning migrants who had started but not currently running a business (Coef. $=0.028 ; p<0.1$ ) and started but presently running a business (Coef. $=0.022$; $p>0.05$ ) seemed increasing anxiety but not quite met the statistical significance.

Of note, family burden to some degree affected the mental health inconsistently in different sub-domains. Having an elderly at home to care seemed increasing the levels of social dysfunction (Coef. $=0.11 ; p<0.1)$ and anxiety (Coef.=0.027; $p<0.1$ ).

Finally, we examined the association of entrepreneurial experience, occupation, and family burden with the GHQ12 sub-domain scores in rural non-migrants (Table 6b). Poor self-assessed health and lower self-assessed family socioeconomic status were associated with higher levels of loss of confidence, social dysfunction, and anxiety. Of note, male non-migrants were associated with reduced levels of loss of confidence, social dysfunction, and anxiety compared with females.
In this study, based on a survey data of 2,100 households conducted in seven provinces where the majority of migrants were from in China, we found that returning migrants were more likely to be associated with elevated anxiety compared with rural non-migrants when adjusting for social and demographic variables. In addition, entrepreneurial experiences reduced the levels of loss-confidence and social dysfunction but increased the levels of anxiety, type of occupation was only associated with anxiety in returning migrants but not in the rural non-migrants.

Our study provided interesting findings on return migration and mental health. Returning migrants appeared to have elevated levels of anxiety when social and demographic variables were controlled. While this may not support the "healthy migrant" effect without a study of migrants and urban residents, our findings seemed supporting the "salmon bias" hypothesis. The "salmon bias" effect seemed being reduced when controlling for type of occupation, entrepreneurial experience, and family care burden, all which were associated with anxiety in the returning migrants but not in the rural non-migrants. However, the elevated levels of anxiety associated with return migration may be partly due to occupation, entrepreneurial experience or family burden. This is because that when these factors were controlled in the analysis, the effect of return migration on anxiety was reduced, and these variables were only associated with anxiety in returning migrants but not in the rural non-migrants. There may be other reasons given that return migration is highly selective and the reasons could be varied (11).

\section{DISCUSSION}


Table 6a. Regression models of mental health outcomes for returning migrants

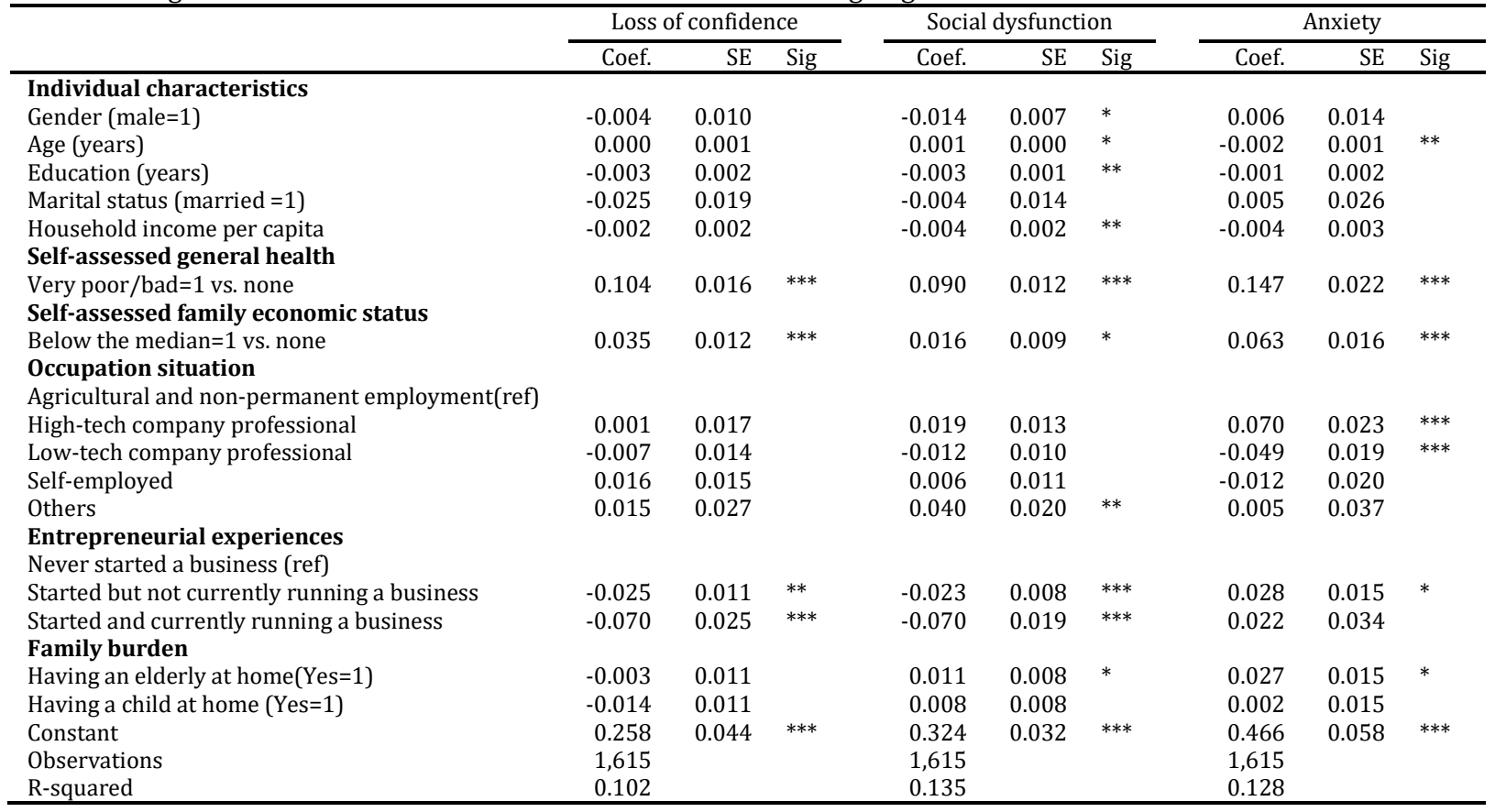

${ }^{* * *} \mathrm{p}<0.01,{ }^{* *} \mathrm{p}<0.05, \mathrm{p}<0.1$.

Table 6b. Regression models of mental health outcomes in rural non-migrants

\begin{tabular}{|c|c|c|c|c|c|c|c|c|c|}
\hline & \multicolumn{3}{|c|}{ Loss of confidence } & \multicolumn{3}{|c|}{ Social dysfunction } & \multicolumn{3}{|c|}{ Anxiety } \\
\hline & Coef. & SE & Sig & Coef. & SE & Sig & Coef. & SE & Sig \\
\hline \multicolumn{10}{|l|}{ Individual characteristics } \\
\hline Gender $($ male $=1)$ & -0.040 & 0.019 & $* *$ & -0.017 & 0.013 & & -0.056 & 0.023 & $* *$ \\
\hline Age (years) & 0.001 & 0.001 & & 0.000 & 0.001 & & 0.000 & 0.001 & \\
\hline Years of schooling & 0.002 & 0.003 & & -0.002 & 0.002 & & -0.004 & 0.003 & \\
\hline Marital status (married =1) & -0.058 & 0.047 & & -0.008 & 0.032 & & 0.026 & 0.057 & \\
\hline Household income per capita & -0.007 & 0.006 & & -0.001 & 0.004 & & 0.011 & 0.007 & \\
\hline \multicolumn{10}{|l|}{ Self-assessed general health } \\
\hline Very poor/bad=1 vs. None & 0.096 & 0.025 & $* * *$ & 0.075 & 0.016 & $* * *$ & 0.186 & 0.030 & $* * *$ \\
\hline \multicolumn{10}{|l|}{ Self-assessed family economic status } \\
\hline Below the median=1 vs. none & 0.050 & 0.021 & $* *$ & 0.034 & 0.014 & ** & 0.102 & 0.025 & $* * *$ \\
\hline \multicolumn{10}{|l|}{ Occupation situation } \\
\hline \multicolumn{10}{|l|}{ Agriculture and non-permanent employment (ref) } \\
\hline High-tech company professional & -0.010 & 0.037 & & -0.022 & 0.024 & & 0.075 & 0.044 & $*$ \\
\hline Low-tech company professional & 0.019 & 0.030 & & 0.027 & 0.020 & & -0.004 & 0.036 & \\
\hline Self-employed & -0.014 & 0.028 & & 0.010 & 0.019 & & -0.010 & 0.034 & \\
\hline Others & -0.017 & 0.036 & & -0.019 & 0.024 & & 0.013 & 0.044 & \\
\hline \multicolumn{10}{|l|}{ Entrepreneurial experiences } \\
\hline \multicolumn{10}{|l|}{ Never-started a business } \\
\hline Started but not currently running a business & 0.008 & 0.022 & $*$ & -0.008 & 0.014 & & 0.060 & 0.057 & \\
\hline Started and currently running a business & 0.015 & 0.035 & & 0.007 & 0.023 & & 0.064 & 0.044 & \\
\hline \multicolumn{10}{|l|}{ Family burden } \\
\hline Having an elderly at home (Yes=1) & 0.015 & 0.021 & & -0.004 & 0.014 & & -0.016 & 0.025 & \\
\hline Having a child at home (Yes=1) & -0.013 & 0.019 & & 0.016 & 0.012 & & 0.039 & 0.022 & $*$ \\
\hline Constant & 0.128 & 0.097 & & 0.272 & 0.064 & $* * *$ & 0.152 & 0.116 & \\
\hline Observations & 568 & & & 568 & & & 568 & & \\
\hline R-squared & 0.218 & & & 0.208 & & & 0.248 & & \\
\hline
\end{tabular}

${ }^{* * *} \mathrm{p}<0.01,{ }^{* *} \mathrm{p}<0.05,{ }^{*} \mathrm{p}<0.1$;

Multiple regression analysis of returning migrants provide evidence for the other hypotheses we proposed. In returning migrants, occupation was significantly associated with levels of anxiety. We found that high-tech company profess- ionals seemed having elevated levels of stress but low-tech company professionals seemed having reduced levels of anxiety, compared with agricultural employment. In addition, the entrepreneurship in returning migrants had gene- 
rally reduced levels of loss of confidence and social dysfunction, but in contrast, it appeared increasing the levels of anxiety. This could be due to the selectivity (e.g., success or failure) and reasons for returning(6). In terms of family burden, returning migrants with the elderly at home to care did increase the levels of anxiety, this probably was the reason for some returnees.

Of note, we did not find significant evidence for association of occupation, entrepreneurship, and family burden with sub-domain scores in rural non-migrants. Poor self-assessed health and self-assessed family economic status were very significant factors that affect the mental health in all three domains of loss of confidence, social dysfunction and anxiety, in rural non-migrants as well as returning migrants.

About the dimensions of GHQ-12 item, Freidman analyzed the data from the 2008 wave of the Rural to Urban Migration in China (RUMiC) survey and indicated that GHQ-12 was two dimensions in Chinese migrants - coping /engagement and stress/depression (38), which represent the nature of the GHQ aimed to measure - positive or negative, but also fit the psychological theory. However, others (37) and the data from this study showed a three-dimensional measure. This would be caused by different definition for migration: the RUMiC is migrants only, and this study focused on both returning migrants (who ever migrated out but now live in original rural areas) and non-migrants.

Our study may have some implications for policy. The analysis of psychological adjustment among returning migrants may have some policy implications for local governments to promote social integration. As occupational stability and family burden have a significant impact on the psychological adjustment of returning migrants, local governments should assist in employment and creation of an entrepreneurial environment for returning migrants, providing supports that are more effective for the elderly to alleviate the worries and family burden of returnees.

\section{Limitations}

There are some limitations to this study. First, the study lacks participants of staying migrants, which would help test the "healthy migrant" effect. Second, the measurement of mental health was based on a simple GHQ-12, which may not measure the psychosocial well-being comprehensively. In addition, previous studies indicate that returning migration is selective and due to complicated reasons, we failed to include related information.

\section{CONFLICTS OF INTEREST}

The authors declare that there is no conflict of interest regarding the publication of this paper.

\section{ACKNOWLEDGEMENT}

The Economic and Social Research Council of the UK (ESRC, ES/L005700/1) funded the research, Impact of return migration on rural economic development in China-with implications for Vietnam.

\section{APPENDIX}

\section{GHQ-12 Questionnaire}

1. Lost much sleep over worry $(\mathrm{N})$

2. Felt constantly under strain $(\mathrm{N})$

3. Been able to concentrate on whatever you are doing (P)

4. Felt that you are playing a useful part in things (P)

5. Been able to face up to your problems (P)

6. Felt capable of making decisions about things (P)

7. Felt you couldn't overcome your difficulties (N)

8. Been feeling reasonably happy, all things considered (P)

9. Been able to enjoy your normal day to day activities (P)

10. Been feeling unhappy and depressed $(\mathrm{N})$

11. Been losing confidence in yourself $(\mathrm{N})$

12. Been thinking of yourself as a worthless person $(\mathrm{N})$

Notes:

1) The six positive questions are $3,4,5,6,8$ and 9. They were coded from the most positive to the least positive: $0=$ Better than usual, 1=same as usual, 2= Less than usual, 3=Much less than usual;

2) The six negative questions are 1, 2, 7, 10, 11 and 12. They were coded from the least negative to the most negative: $0=$ Not at all, 1=No more than usual, 2=Rather more than usual, 3 = Much more than usual;

3) For an individual, the scores are usually added so that the total score ranges from 0 to 36 ; an individual with total score of 14 or more is often considered a cutoff for "caseness"(40).

\section{SUPPLEMENTARY TABLES}

Table S1, Table S2

\section{REFERENCES}

1. Ren Y. Urbanization consisting of "going into the city" and "returning home". Jiangsu Social Sciences. 2010;3:108-12.

2. Li C. Urban and rural immigrants and social mobility. Jiangsu Social Sciences. 2007; 2:88-94.

3. Cai H, Wang JA. A study on migrant workers' permanent migration Intentions. Sociological Research. 2007;6:86-113.

4. Zhou H. The trend of family migration and its influencing factors in China's population migration. Population Research. 2004;28(6):60-9.

5. Duan C, Liu T, Lu L. Research on current population flow situation and its impact in China. Shandong Social Sciences. 2017;9:63-9.

6. Wang WW, Fan CC. Success or failure: selectivity and reasons for return migration in Sichuan and Anhui, China. Environment and Planning A. 2006;38:939-58.

7. Zhao Y. Causes and consequences of return migration: recent evidence from China. Journal of Comparative Economics. 2002;30(2):376-94.

8. Chan KW. The global financial crisis and migrant workers in China: 'there is no future as a labourer; returning to the village has no meaning'. International Journal of Urban and Regional Research. 2010;34(3):659-77.

9. Zhang H. The Analysis on Wishes of Returned Migrant Workers about Entrepreneurship and the Study of Policy Supporting System in Jiangxi Province (Doctoral disser-tation). 2010: Jiangxi University of Finance and Economics.

10. Han J, Cui CY. Returning migrants and entrepreneurship: based on empirical study on a survey of "a hundred counties" in China. In Han L edited, Research on the Strategy of Migrant Workers in China. 2009, P181-220. Shanghai: Far East Publishing House. 
11. Wang WW, Fan CC. Success or failure: selectivity and reasons of return migration in Sichuan and Anhui, China. Environment and Planning A. 2006;38:939-58.

12. Miao D, Liang $\mathrm{Z}, \mathrm{Wu} \mathrm{Y}$. Interprovincial return migration in China: Individual and contextual determinants in Sichuan province in the 1990s. Environment and Planning A. 2013; 45(12):2939-58.

13. Miao D, Liang Z, Wu Y. Interprovincial Return Migration in China: Individual and Contextual Determinants in Sichuan Province in the 1990S. Environment and Planning A: Economy and Space. 2013;45(12):2939-58.

14. Xu H. Return migration, occupational change, and self-employment: the case of Wuwei County. China Perspectives [Internet]. 2010. Available from: http://journals.openedit-ion.org /chinaperspectives/5343.

15. Ren Y, Shi W. Determinants and Effects of Return Migration in China. Population Research. 2017;41(2):71-83.

16. Jin L. Migration, Relative Deprivation, and Psychological Well -Being in China. American Behavioral Scientist. 2016;60 (56):750-70.

17. Kafle K, Benfica R, Winters P. Does relative deprivation induce migration? Evidence from sub-Saharan Africa. IFAD RESEARCH SERIES; 2018.

18. Stark O, Wang YQ. A Theory of Migration as a Response to Relative Deprivation. University of Bonn, Center for Development Research (ZEF); 2000.

19. Fennelly K. The "healthy migrant" effect. Minn Med. 2007;90 (3):51-3.

20. Puschmann P, Donrovich R, Matthijs K. Salmon Bias or Red Herring?: Comparing Adult Mortality Risks (Ages 30-90) between Natives and Internal Migrants: Stayers, Returnees and Movers in Rotterdam, the Netherlands, 1850-1940. Hum Nat. 2017;28(4):481-99.

21. White M. International Handbook of Migration and Population Distribution: Spinger; 2016.

22. Qi Y, Niu J, Mason W, Treman D. China's internal migration and health selection effect. Population Research. 2012;36 (1):102-12.

23. Buttner EH. Entrepreneurial Stress: Is it Hazardous to Your Health? Journal of Managerial Issues. 1992;4(2):223-40

24. Lewin-Epstein N, Yuchtman-Yaar E. Health risks of self-employment. Work \& Occupations. 1991; Work \& Occupations (18):3.

25. Loukissa DA. Family burden in chronic mental illness: a review of research studies. Journal of Advanced Nursing. 1995; 21(2):248-55.

26. Bradley D, Roberts J. Self-Employment and Job Satisfaction: Investigating the Role of Self-Efficacy, Depression, and Seni- ority. Journal of Small Business Management. 2004;42 (1):37-58.

27. Hundley G. Why and When Are the Self-Employed More Satisfied with Their Work? Industrial Relations A Journal of Economy \& Society 2001;40(2):293-316.

28. Noonan AE, Tennstedt SL. Meaning in caregiving and its contribution to caregiver well-being. Gerontologist. 1997;37 (6): 785-94.

29. Romppel M, Braehler E, Roth M, Glaesmer H. What is the General Health Questionnaire-12 assessing? Dimensionality and psychometric properties of the General Health Questionnaire -12 in a large scale German population sample. Compr Psychiatry. 2013;54(4):406-13.

30. Goldberg DP, Hillier VF. A scaled version of the General Health Questionnaire. Psychol Med. 1979;9(1):139-45.

31. Goldberg DP, Blackwell B. Psychiatric Illness In General Practice. A Detailed Study Using A New Method Of Case Identification. The British Medical Journal. 1970;2 (5707): 439-43.

32. Chen CS, Tsang HY, Chong MY, Tang TC. Validation of the Chinese Health Questionnaire (CHQ-12) in community elders. Kaohsiung J Med Sci. 2000;16(11):559-65.

33. Liang Y, Wang L, Yin X. The factor structure of the 12-item general health questionnaire (GHQ-12) in young Chinese civil servants. Health Qual Life Outcomes. 2016;14(1):136.

34. Goldberg D, Williams PA. A User's Guide to the General Health Questionnaire. Windsor, UK.: NFER-Nelson; 1988.

35. Jackson C. The general health questionnaire. Occupational Medicine. 2007;57(1):79.

36. Goldberg DP. The detection of psychiatric illness by questionnaire; a technique for the identification and assessment of non-psychotic psychiatric illness. London, New York,: Oxford University Press; 1972. xii, 156 p. p.

37. Graetz B. Multidimensional properties of the General Health Questionnaire. Soc Psychiatry Psychiatr Epidemiol. 1991;26 (3):132-8.

38. Friedman J. The relationships between the housing arrangements and subjective wellbeing of rural-to-urban migrants in China. The 10th IZA Annual Migration Meeting $\left(\mathrm{AM}^{2}\right)$ and 4 th Migration Topic Week, Jerusalem, Israel, June 3-7, 2013.

39. Guan M, Han B. Factor Structures of General Health Questionnaire-12 Within the Number of Kins Among the Rural Residents in China. Frontiers in Psychology. 2019;10 (1774).

40. Lundin A, Åhs J, Åsbring N, Kosidou K, Dal H, Tinghög P, et al. Discriminant validity of the 12 -item version of the general health questionnaire in a Swedish case-control study. Nordic Journal of Psychiatry. 2017;71(3):171-9.

Copyright (C) 2020 by Global Clinical and Translational Research

\section{How to cite this article:}

Ren, Q Wang T, Shen J, Wang WW, Zhu Y. Impact of Occupation and Family Burden on Psychological Adjustment in Returning Migrants. Glob Clin Transl Res. 2020;2(2):16-26.

DOI: $10.36316 /$ gcatr.02.0026. 